\title{
TITLE:
}

\section{Projection and Large Area Displays of Artworks for Public Exhibits}

$\operatorname{AUTHOR}(\mathrm{S}):$

Tosa, Naoko; Yang, Qin; Nakatsu, Ryohei

\section{CITATION:}

Tosa, Naoko ... [et al]. Projection and Large Area Displays of Artworks for Public Exhibits. Evolution of Technology and Future of the Creative Contents Industry for the Fourth Industrial Revolution 2019: 47-56

ISSUE DATE:

2019-11

URL:

http://hdl.handle.net/2433/245366

RIGHT: 


\title{
Projection and Large Area Displays of Artworks for Public Exhibits
}

\author{
Naoko Tosa', Qin Yang', Ryohei Nakatsui ${ }^{2}$ \\ 'Graduate School of Advanced Integrated Studies in Human Survivability, Kyoto University \\ 2 Academic Center for Computing and Media Studies, Kyoto University
}

\begin{abstract}
Owing to the advance of projection and large areadisplays, art exhibition at public area became possible. Wehave various experiences of exhibiting our artworks in two ways; exhibition using projection mapping and one using large LED screens. Based on such experiences wediscuss relevant ways of public art exhibition.
\end{abstract}

Keywords: Media art, fluid art, projection mapping, large-area display

\section{I . BACKGROUND AND OBJECTIVES}

In the long history of art, artworks have been mainly exhibited at museums or displayed at an art corrector's house. It was difficult for people to appreciate them at public spaces such as parks, city centers, etc. Owing to the technological advance of projectors and large-screen displays, however, now it is possible to show artworks in open public places to many people. Although it was only at special occasions such as visiting museum for people to appreciate artworks, these emerging new technologies give good chances for them to appreciate artworks in their everyday life. Based on such motivation, we have spent lots of effort in exhibiting our artworks in the form of projection mapping and also large area displays. This paper describes features of our artworks, and also our experiences of exhibiting them using these technologies This paper is organized as follows. Chapter 2 describes features of artworks we have been 
creating focusing to extract beauty hidden in nature. Chapter 3 explains projection mapping, which is one method of showing our artworks in public spaces, and describes two big projection mapping events in which we showed our artwork. Chapter 4 explains exhibitions using big LED screens, which is another method of showing our artworks in public spaces, and describes two exhibitions using big LED screens. And finally in Chapter 5 we summarize our experiences of showing our artworks using projection mapping and big LED screens.

\section{MEDIA ART BASED ON VISUALIZATION OF HIDDEN BEAUTY IN NATURE}

\subsection{Basic Concept}

There are various types of beauty hidden in nature. One good example is milk crown [1]. As is well known, a drop of milk fallen on a glass of milk creates a very beautiful form. Although this cannot be seen by our naked eyes, by shooing the phenomenon using a high speed camera and thus by extending time, it becomes possible for us to watch this beautiful phenomenon. Based on this, we have been working on the creation of artworks by shooting various kinds of physical phenomena based using a high speed camera [2].

\subsection{Sound of Ikebana}

It is well known that liquid such as water or paint jumps up by giving it various vibrations. As far as we watch the phenomenon by our naked eyes, there is nothing interesting nor appealing. However, by giving sound vibrations to paints with various colors and by shooting the phenomenon using a high speed camera, we found that various beautiful and mysterious forms, which are similar to Ikebana (Japanese flower arrangement), are created. We have carried our various experiments based on this idea. And by collecting various video clips and editing them, we have created a media art called "Sound of Ikebana [3]." Figure 1 shows an example of scenes of Sound of Ikebana. Sound of Ikebana consists of four short videos, each of which represents one of four seasons in Japan. It uses specific colors to represent flowers in each season. By utilizing various types of color paints and liquid, we tried to express Japanese flowers in each season, such as palm and cherry in spring, cool water and morning glory in summer, red leaves in autumn, and snow and camellia in winter. Also, we tried to express various color variations such as prayerful colors of Buddhism, Japanese "Wabi-sabi (taste for quiet and simple)" colors, colors of delicious food, cute colors of 
"Cool Japan," gorgeous colors featuring Christmas and New Year season, etc.

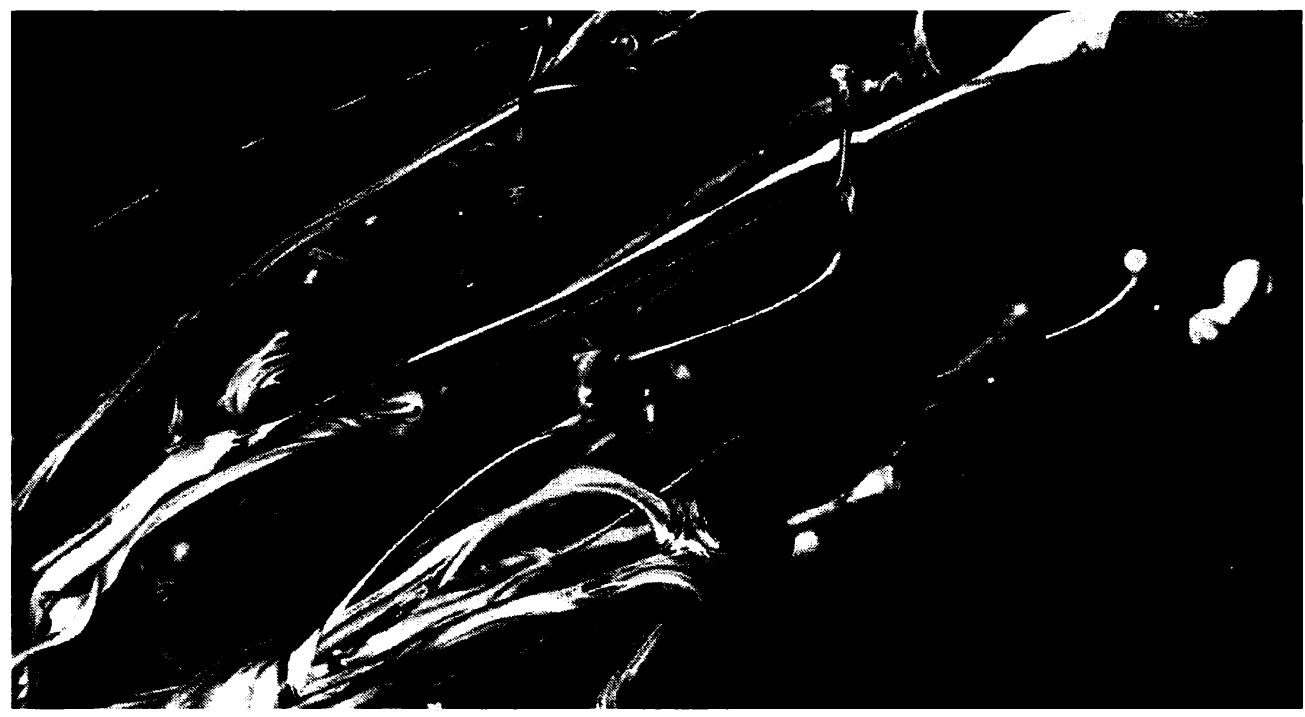

Fig. 1 I Soene of "Somond of lkebana"

\section{PROJECTION MAPPING}

Projection mapping is a technology to project images or videos on 3D objects [4]. Conventional way of projectionusing a projector is to project images on a rectangular white screen. However, recently new demand to project images on a very big object such as a building. As the technology for a projector with ultra-high luminance has emerged, this became possible. As a big object such as a building usually has $3 \mathrm{D}$ form, for the projection mapping it is necessary to prepare $3 \mathrm{D}$ model of the object, to deform images to be projected according the 3D model and to carry out projection. As recently there are many software tools to realize this, it is becoming easy to carry out projection mapping even without detailed knowledge about 3D projection. To carry out projection mapping on a big object has various merits. One is that many people, for example more than several thousands of people, can appreciate the projected images together. Also, by projecting images on a building would be able to change its original form and can give people a feeling that the object has changed into another one. For example, a building could become a huge robot standing in front of viewers. It would be good and appropriate for artistic contents to be shown using projection mapping, as it opens a 
chance for many people to appreciate artworks ina public space. We have carried out big projection mapping event using our artworks as follows.

\subsection{Projection Mapping at ArtScience Museum in Singapore}

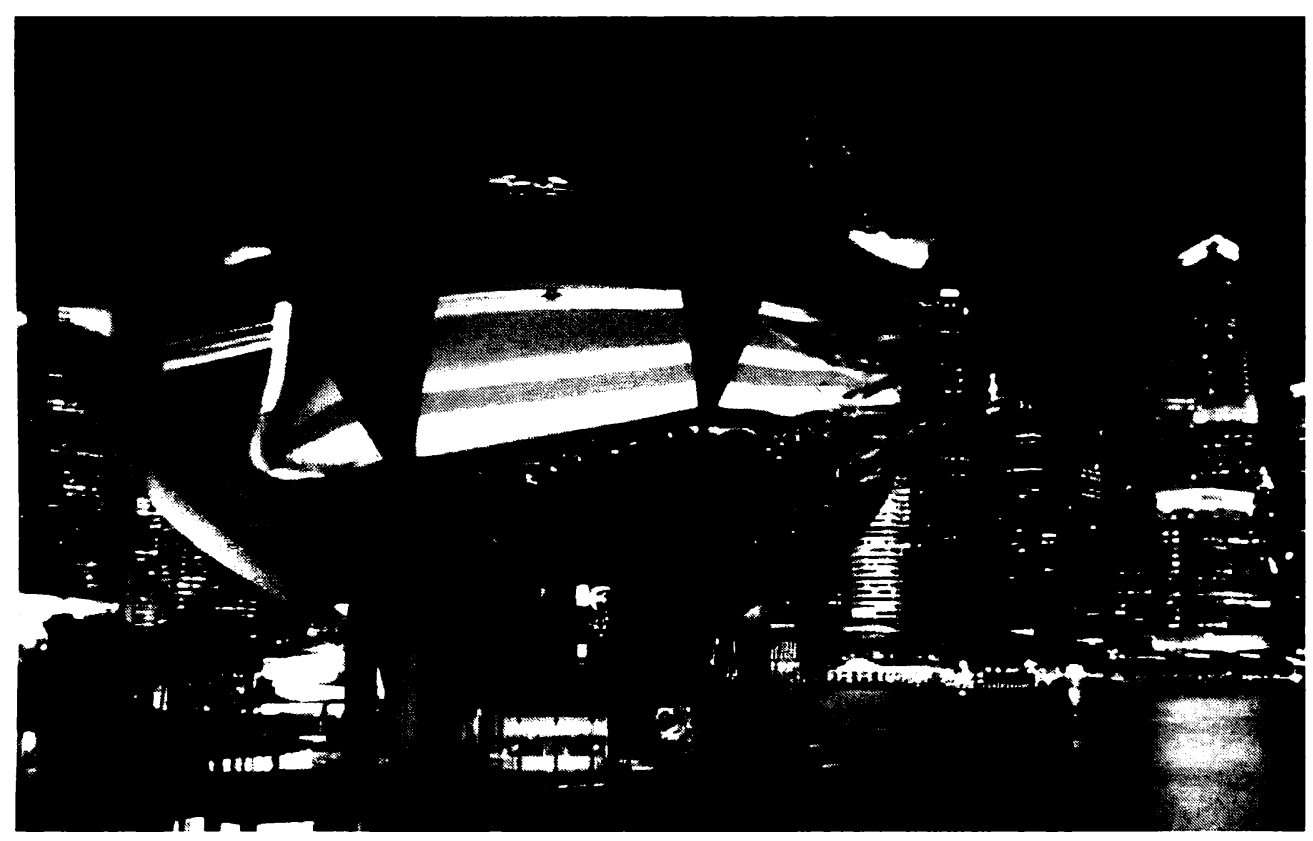

Fig. 2 Projection mapping of "Sound of Ikebana" at ArtScience Museum in Singapore

In February 2013 we carried out a projection mappingof "Sound of Ikebana" at a museum called ArtScience Museum, in Marina Bay area in Singapore. As Singapore does not have clear distinction among four seasons, we thought that showing Sound of Ikebana to Singapore people would be a good chance to let them know four seasons in Japan and at the same time to appeal them Japanese culture represented by Ikebana. The projection mapping event gathered more than ten thousand people and were well welcomed by them [5]. Figure 2 shows a scene of the projection mapping of Sound of Ikebana at the Art Science Museum. 


\subsection{Projection Mapping at Kyoto National Museum}

2014 was the year of 400th anniversary of RIMPA, which is one of traditional Japanese art schools that was originated in the Muromachi era by Tawaraya Sotatsu in Japan. It has the feature of having gorgeous combination of vivid colors and also original unique composition. As Naoko Tosa, one of us, acknowledges herself as a successor of RIMPA, we wanted to carry out a projection mapping of her artwork somewhere in Kyoto. As we succeeded in obtaining financial support from the Kyoto Prefectural Government, in March of 2014 we carried out a projection mapping using a new video artwork called " 21 th Century Legend of Wind God and Thunder God." In the creation process, using the basic concept of Sound of Ikebana, we carried out collaborations with leaders of Kyoto traditional arts such as a director of one of flower arrangement schools in Kyoto, a young Kyogen (comical Noh) player, and created the video artwork. The four day projection mapping event attracted nearly 20,000 Kyoto citizens and tourists. Figure 3 shows a scene of the projection mapping event.

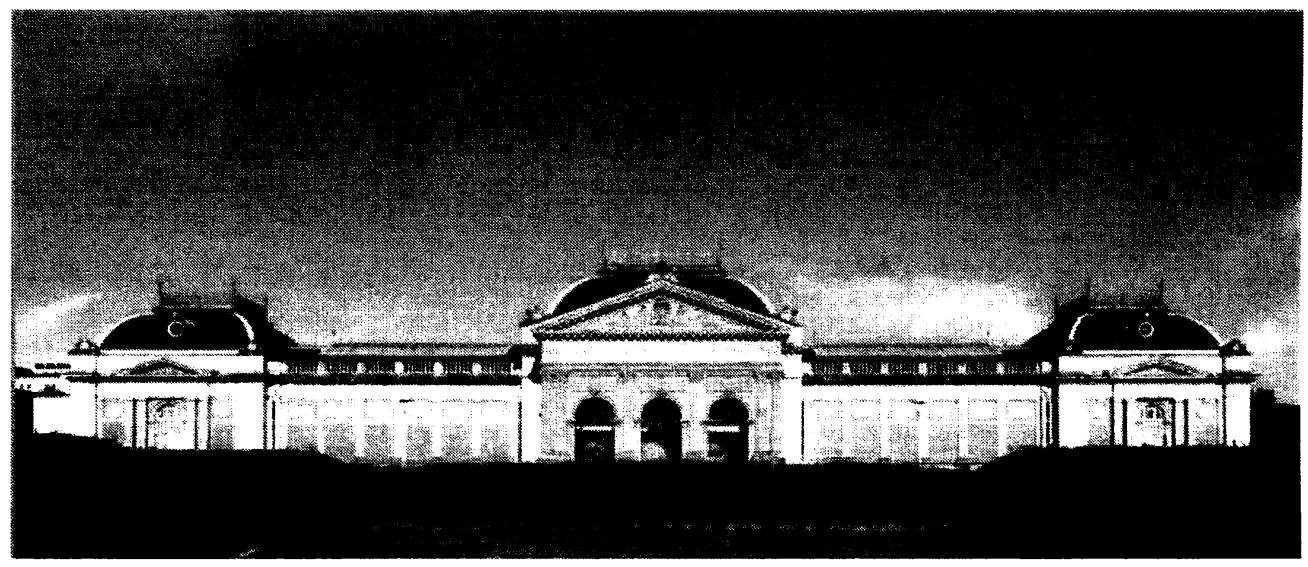

(a) Outlook of Kyoto National Museum 


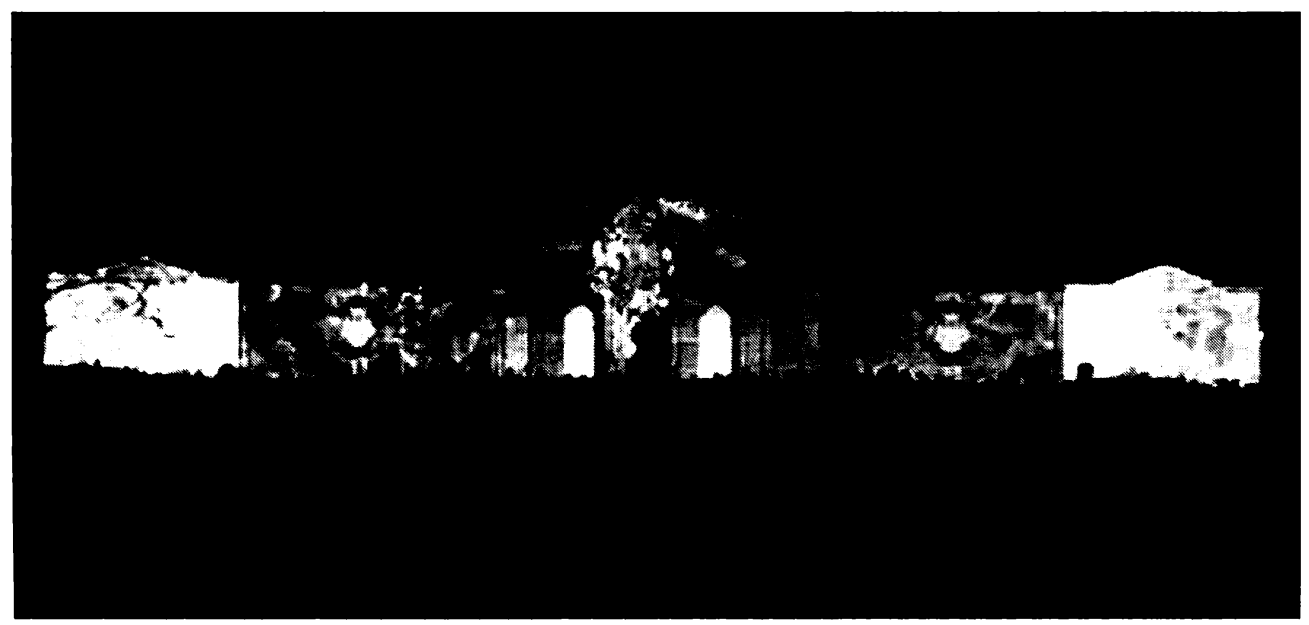

(b) A scene of projection mapping

Fig. 3 Projection mapping celebrating RIMPA

\section{LARGE AREA DISPLAYS}

Until recently LED display was very expensive and therefore, it was very difficult to develop large area displays using LED technology. Owing to the recent technology advance of LED display. it has become far cheaper than before. Therefore, now it is possible to develop large area displays using LED. One way is to design original large area displays by integrating huge amount of small LED lights with three primary colors. Another is that, as there are already standard LED displays with various sizes, by combining them together it is possible to develop a large area display with required size. Different from projection using projectors, a merit of using LED display is that even during day time LED display can provide vivid images. Utilizing such a merit we have carried out several exhibits using our art contents.

\subsection{Large Area Display at Yeosu EXPO}

Yeosu World Expo 2013 was held in Yeosu, South Korea for three months in 2012. The main theme of the Expo was "Ocean and Its Future." Among various pavilions, in the central part of the Expo venue, there was a main street covered by a ceiling called the Expo Digital Gallery as is shown in the right side photo of Fig. 4. The reason why it was called the Expo Digital Gallery is that on the inner side of the ceiling they 
developed a huge LED screen of $250 \mathrm{~m} \times 25 \mathrm{~m}$. As the Expo organization committee called for proposal of art using the huge screen, we applied and our proposal was accepted. To match wit the main theme of the Expo, we created an artwork called "Four God Flags" under the concept of "Asia is one" and exhibited the artwork on the LED screen during the Expo period (left side photo of Fig.4) [6]. The Expo organization committee was glad as the Expo satisfied the three major elements required for each Expo; the number ofncustomers, the evaluation by experts, and the implementation of the basic concept. We were given Expo Award by the committee because of our contribution to the Expo.

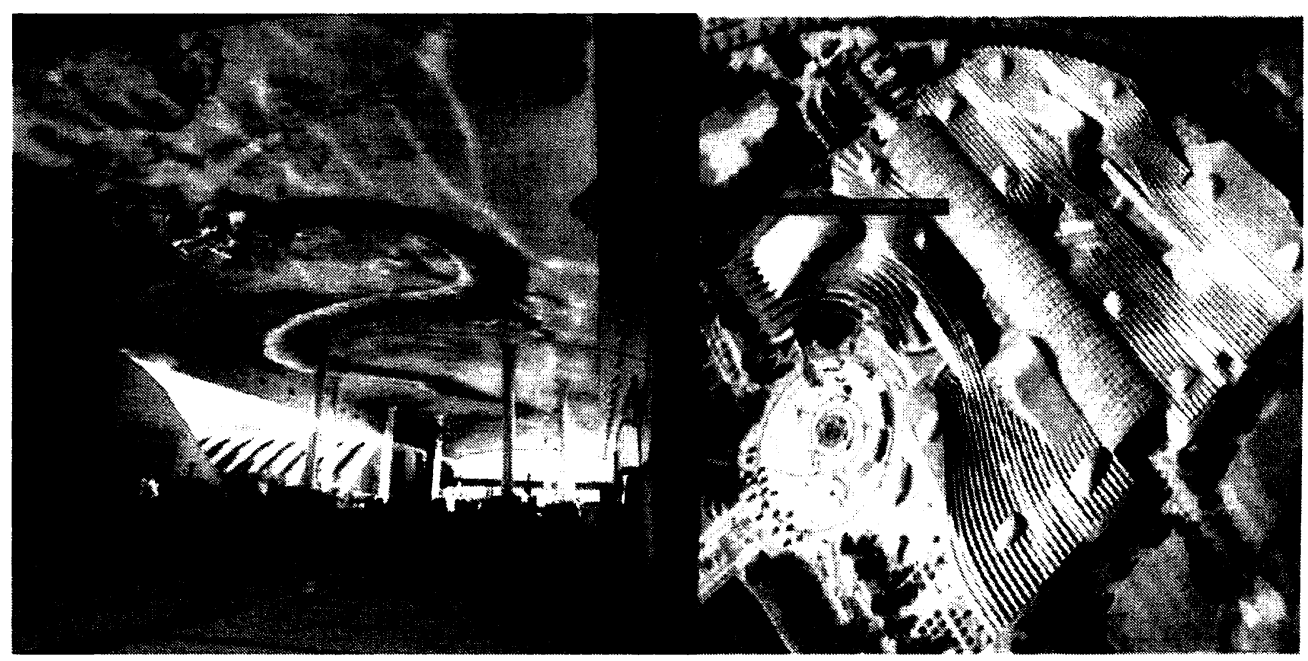

Fig. 4 Exhibit of our artwork at Yeosu EXPO.

\subsection{Large Area Display at Times Square, New York}

In Times Square, New York, NPO called Times Square Alliance has been doing a large area display of artworks using many digital signages installed in and around Times Square area. Based on the concept of making Times Square, that has been known as a tourism center in New York, as an art center, they started this activity in the 1980's. At first, they did the exhibition using only one small LED display there. But their activity was gradually recognized and they could attract more and more sponsors. And now they are carrying out the event using more than 60 digital signages there. The exhibit is called Times Square Art and every evening for three minutes, from 11:57pm until midnight, exhibit of artworks featuring one artist for one month is carried 
out. As the application for the exhibit is open, we submitted our application to Times Square Alliance and our application was fortunately accepted by them. Based on this we carried

out the exhibition of "Sound of Ikebana" in April 2017. Figure 5 shows a scene of the exhibit.

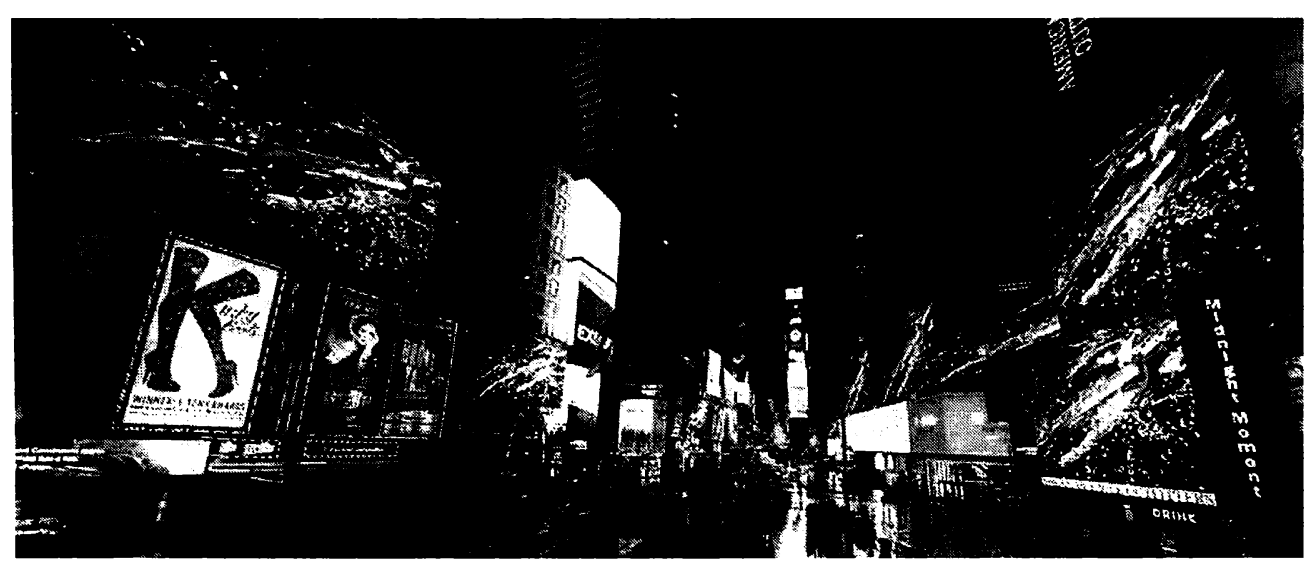

Fig. 5 Exhibit of "Sound of Ikebana" at Times Square in New York

\subsection{Large Area Display at Taipei}

In 2018 we were invited to do a video art exhibition at Dong Gallery in Taipei. Taiwan. The gallery has a large LED screen of about $50 \mathrm{~m}$ length and $3 \mathrm{~m}$ height. The display is set along a wide road in business area. Therefore, this is a good chance for us to exhibit our artwork not in art areas such as museums but business area where the exhibit of art is not common. We carried out the exhibition of "Sound of Ikebana" there for several months. Figure 6 shows a scene of the exhibit. Based on this exhibit we recognized that art exhibition in business area could change the atmosphere of the business are. 


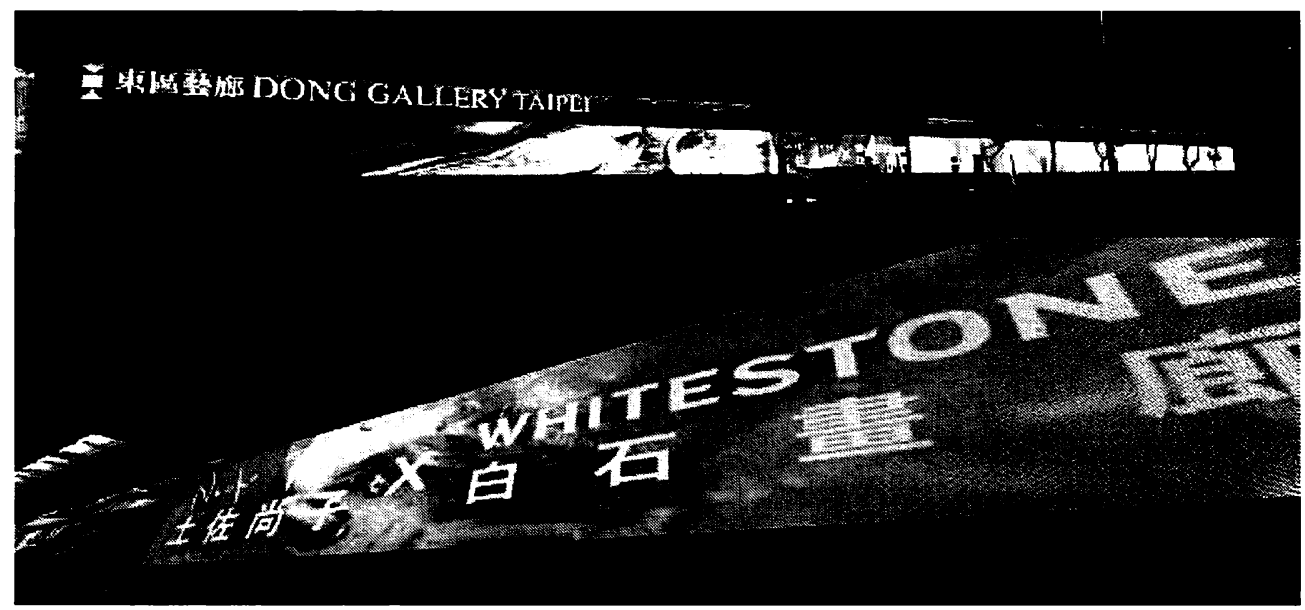

Fig. 6 Exhibit of "Sound of Ikebana "at Dong Gallery in Taipei, Taiwan

\section{DISCUSSION}

We have had various experiences of exhibiting our artworks in the form of projection mapping and large area displays. Based on our experiences, we have the following thoughts.

(1) Projection mapping and large area displays are good ways of exhibiting artworks in public areas. By doing so. it becomes possible for many people. who rarely have experiences of appreciating artworks, to appreciate artworks and thus become more familiar with art and culture.

(2) Projection mapping and large area displays have their own merit and demerit. For example, as projection mapping uses projectors, which are movable, the setting of projection mapping is very flexible regardless of the place and form of objects on which projection is carried out. On the other hand, even if projectors with very high luminance are used, it is almost impossible to see the exhibits during day time. Large area displays have opposite merit and demerit. Therefore, it is required to choose one of these exhibit methods depending on situations. 


\section{REFERENCES}

[1] K. Rouslan, and G. M. Hosmy, "Crown-forming instability Phenomena in the Drop Splash Problem," Journal of Colloid and Interface Science, Vol.331, pp.555-559 (2009)

[2] N. Tosa, Y. Pang, Q. Yang, and R. Nakatsu, "Pursuit and Expression of Japanese Beauty Using Technology," Special Issue "The Machine as Artist (for the 21st Century)," Arts Journal, MDPI, Vol.8, No.1, 38, DOI 10.3390/arts 8010038 (2019).

[3] Y. Pang, L. Zhao, R. Nakatsu, and N. Tosa, "A Study of Variable Control of Sound Vibration Form (SVF) for Media Art Creation," 2017 Int. Conf. on Culture and Computing, pp.136-142 (2017).

[4] G. Blokdyk, "Projection Mapping A Complete Guide," 5StarCooks (2018).

[5] N. Tosa, R. Nakatsu, and Y. Pang, "Creation of Media Art Utilizing Fluid Dynamics," 2017 Int. Conf. on Culture and Computing, pp.129-135 (2017).

[6] N. Tosa, J. Park, and R. Nakatsu, "Korea Expo 2012 and Its Digital Gallery Work Focusing Asian Four Gods, Creation of Media Art Utilizing Fluid Dynamics," 2013 Int. Conf. on Culture and Computing, pp.45-50 (2013 